\title{
Propuesta agustiniana de filosofía política
}

\author{
El "quid medium naturale humanum" \\ fundamento de la inter-comunicación polarizada \\ iglesia - estado
}

TARSICIO JÁÑEZ BARRIO

\section{Consideración previa}

La "civitas agustiniana" se mueve en un doble nivel: metahistórico e histórico. En el nivel metahistórico (místico) la "civitas" adquiere un sentido estricto o propio, equivalente a "reino"; en el histórico su sentido es derivado, secundario (impropio), equivalente a ciudad (res-publica) bien religiosa (Iglesia), bien política (Estado). Esta consideración previa, verdadero fundamento de la filosofía política agustiniana, nos lleva, seguidamente, a establecer, en primer lugar, la incompatibilidad absoluta entre las dos civitas meta-históricas (Civitas Dei et Civitas terrena), y en segundo lugar, a tres diferencias entre unas y otras "civitates": la no identidad entre "Civitas Dei" e Iglesia, la no equivalencia entre "Civitas terrena" y Estado, y la gran diferencia (distinción) entre Iglesia y Estado. Desde aquí, creemos poder hablar de la conexidad real entre Iglesia y Estado, centrándola sobre el punto común que llamamos "quid medium naturale-humanum", siempre que no se conciba un Estado radicalmente injusto e inhumano.

\section{Sentidos de "civitas" según su doble nivel:}

1.a. Nivel metahistórico-místico: Sentido estricto, propio-primario: "Civitas Dei et Civitas terrena"

En este sentido propio-estricto, la "civitas" es realidad meta-histórica-mística. Ambas "civitates" están encarnadas en la historia, inextrica- 
blemente mezcladas, como el trigo y la cizaña. Hay que esperar a la siega (al fin de los tiempos) para poder separar el trigo de la paja (de la cizaña) ${ }^{1}$, pero su distinción es nítida debido a la calidad de su amor: "amor Dei et sui". Y mientras, una es peregrina en la historia, la otra tiene aquí establecida su tienda (vive para sí misma). La Ciudad de Dios (Reino de Dios) es meta-histórica-mística, pero existe ya aquí en la tierra (está ya en este mundo pero no es de este mundo), por eso no se puede confundir con la ciudad Ideal de Platón, que no existe más que en el pensamiento ${ }^{2}$. La "Civitas terrena" (Reino del diablo) es también metahistórica, porque estando subsumida totalmente en lo mundano y terreno aspira a perpetuarse en el más allá (aunque en vano).

Agustín divide toda la humanidad en dos ciudades: Ciudad de Dios (Jerusalén) y Ciudad terrena" (Babilonia), ocasionalmente ciudad del diablo ${ }^{3}$, ciudades en sentido místico (mystice): "amor Dei et amor sui"". La Ciudad de Dios que existe ya aquí guiada por el amor de Dios, en contraste con la Ciudad Terrena guiada por el amor de sí mismo (amor sui):no ordenada hacia Dios, sino exclusivamente hacia sí mismo (ciudad terrena, presuntuosa, autosuficientes, independiente ${ }^{5}$.

Consideradas en su especificidad, las dos ciudades metahistóricas, avanzan hacia la siega (procursus et fines debiti), cuando la "Civitas terrena-diaboli" tendrá su aniquilación, y la "Civitas Dei" tendrá la plenitud de su triunfo por el amor en el "gaudium de Veritate", en la felicidad sin fin ${ }^{6}$. Tal es el sentido optimista de la historia por el triunfo en la Ciudad de Dios o Reino de Dios.

Ambas discurren sin reconciliación posible alguna y sin punto alguno común de encuentro, sin embargo, sus miembros están mezclados en las sociedades (civitates) históricas hasta la siega?

${ }^{1}$ Ciu. 1, 35; Ib., 11,1. Ib., 18, 49. Ib., 20, 9, 1 .

${ }^{2}$ Cf. Diccionario de San Agustín (Civitate Dei, De), 273.

${ }^{3}$ Ciu. 17, 20, 2; Ib. 17,21, 1 .

${ }^{4} I b ., 14,28 ; I b ., 15,1,1$.

${ }^{5}$ Ib., 10, 25; Ib. 10, 28-29.

${ }^{6} I b ., 1,35 ; I b ., 10,32,3-4 ; I b .15,21 ;$ Ib. 22, 30,6; Conf., 10, 23, 33; Ep. ad Firmum: BA 33, $171 ;$ Retr. $2,43,20$.

${ }^{7} I b ., 14,4 ; I b ., 14,13$ y $15 ; I b ., 20,9$. 
1.b. Nivel histórico: Sentido derivado (lato, secundario; común): "Iglesia-Estado":

Este sentido derivado de "civitas" -hoy es para nosotros su sentido natural, ordinario, normal- expresa la realidad histórica-empírica, es la "civitas en la historia", que se desarrolla como "civitas religiosa y civitas política", sin confundirse pero mezclados sus miembros. A la primera la llamamos, 'Ecclesia', y a la segunda, 'Estado'. La primera tiene por fin específico-prioritario el gozo eterno (sobrenatural), mientras que el segundo tiene por fin específico el disfrute temporal (natural).

La 'Ecclesia' histórica, ciudad de Dios "in fieri", adquiere diversos sentidos porque goza de una compleja dimensión ${ }^{8}$. Y el 'Estado', que puede ser humano o inhumano, según acepte y se fundamente en el derecho de la naturaleza humana (variable-perfectible e histórica), o se fundamente $\mathrm{y}$ acepte un derecho absoluto y estrictamente positivo.

La diferencia real entre estas dos "civitates" es tan clara como claros son sus motivos, orientaciones y fines. "Para el observador terrenal -dice E.L. Fortin- los acontecimientos históricos conservan su fundamental obscuridad. La vida de estas dos sociedades históricas-temporales, considerada en su totalidad, aparece, no como una progresión (procursus) ordenada hacia un fin determinado, sino como un simple proceso (excursus) por el cual Iglesia y Estado viven su exigencia terrena, con su mezcla característica de éxitos y fracasos". Sin embargo, para el desprejuiciado captador del discurrir agustiniano por la historia resulta por demás claro el verdadero "procursus et fines debiti" de ambas "civitates", y no tanto el

${ }^{8}$ Preludio y núcleo de la Ciudad de Dios: La religión cristiana-doctrina cristiana-república consagrada: camino universal de liberación preanuncia ya desde la antigüedad (Abrahán) un cielo nuevo; era ya profecía y preludio de la Ciudad de Dios. Religio christiana-Iglesia-Ciudad de Dios y ciudad terrena andan entreveradas y mezcladas (in hoc saeculo perplexas atque permixtas) en este siglo (Ciu. 10,32,1-4; Ib., 15, 1-2); “communitas fidei”, institución jerárquica-ministerial (clerical, secular), Iglesia sacramental-litúrgica, Iglesia realidad sociológico-estatal (Estado Vaticano). Iglesia terrena e Iglesia celeste, Iglesia temporal (en espacio y tiempo) e Iglesia Ciudad de Dios (Reino de Dios y Reino de los cielos), Iglesia peregrina e Iglesia escatológica, Iglesia institución e Iglesia cuerpo de Cristo, Iglesia entidad sociológica, Iglesia santa e Iglesia pecadora....; "civitas-urbs": recinto físico (En. Ps. 64, 2; cf. "Diccionario de San Agustín" (Iglesia-ecclesia), 664.

${ }^{9}$ E.L. Fortin: a.c., 203. Ciu. 15,1-2. "mortalis excursus" de ambas ciudades. 
"excursus" que también ${ }^{10}$, entendidos uno y otro "excursus et procursus", dentro de la zinzagueante (no rectilínea) pero lineal dialéctica de la historia.

En atención a nuestro propósito especificaremos un poco más en detalle, la no identidad, o las diferencias, entre estas "civitates", con base en el "quid medium naturale", como factor común.

\section{La no identidad entre:}

\section{2.a. "Civitas Dei” y "Ecclesía" iguales y distintas, pero inseparables}

Hay que entender que entre la Civitas Dei y la Ecclesia (Iglesia-institución y Cuerpo de Cristo) se establece una relación dialéctica de identidad y de no identidad ${ }^{11}$. La Iglesia prioritariamente es la congregación activa de una nueva humanidad que se reúne en comunión con Cristo (fe, esperanza y amor de los santos), pero "no llamaría ahora a la Iglesia su reino o reino de los cielos"12.

Iguales y distintas: Agustín se negaba a identificar la Ciudad de Dios, entendida en sentido supremo con los miembros de la Iglesia que se hallaban aún en peregrinación ${ }^{13}$. Una cosa es la Iglesia, reino de los cielos aquí, y otra la Iglesia, reino de los cielos allí. Hay que resaltar con san Agustín, en contra de los donatistas, pelagianos..., el contraste entre la Iglesia presente y la futura unidos en la Cabeza ${ }^{14}$. La presente tiene que decir cada día: Perdona nuestra deudas..., la futura es sin mancha ni ruga:

${ }^{10} \mathrm{Ciu}$. 15, 21: "Propositis itaque duabus civitatibus, una in re huius saeculi, altera in spe Dei, tanquam ex communi, quae aperta est in Adam, ianua mortalitatis egressis, ut procurrant et excurrant ad discretos proprios ac debitos fines, íncipit dinumeratio temporum... "; Ib., 19, 5: ..., vel inchoaretur exortu, vel progrederetur excursu, vel apprenhenderet débitos fines"...; Retr., 2, 43, 2 (excursum earum sive procursum). Ep. 1* A, 1 (ad Firmum): "totitemque procursum, sive dicere malumus, excursum...debitos fines".

${ }^{11}$ Diccionario de San Agustín, 672.

${ }^{12}$ Ciu. 20,9,1-2.

${ }^{13} \mathrm{Ib}$. 20, 9, 1; "Es preciso entender de un modo el reino de los cielos en el que están tanto los que ponen en práctica sus enseñanzas como los que no las ponen... Así el primero, morada mixta, es la Iglesia cual es ahora, el segundo -entrada única- es la Iglesia cual será cuando no haya en ella pecadores. La Iglesia es, pues, ahora el reino de Cristo y el reino de los cielos". Cf. Diccionario de San Agustín, 684; L. Bassols, O.c., 170.

${ }^{14}$ Ench. 56, 15. 
"societas sanctorum, o Ecclesia sanctorum, o sanctorum civitas"; "congregatio civitasque sanctorum", "ipsa est Ecclesia sanctorum"15.

Aunque Agustín, algunas veces, identifica a la Ciudad de Dios con la Iglesia $^{16}$, sin embargo, existe una gran diferencia, porque no cualesquiera miembros de la Iglesia, lo son de la Ciudad de Dios, y a la inversa, muchos que no profesan la fe cristiana, pueden ser miembros de la Ciudad santa ${ }^{17}$.

Podemos resaltar sus principales aspectos diferenciadores: Iglesia terrena-Iglesia celeste; Iglesia histórica-temporal-Iglesia ciudad de Dios (reino de Dios, reino celeste); Iglesia peregrina-Iglesia escatológica (en consumación y plenitud); Iglesia institución-Iglesia cuerpo de Cristo; iglesia como entidad sociológica-Iglesia como vivencia en Cristo (por el Espíritu Santo); Iglesia santa-Iglesia pecadora-empírica (reunión, convocatoria, casa de Dios, templo de Dios) mezcla de santos-buenos y pecadores); Iglesia carismática-Iglesia jerárquica, con sus ritos sacramentales $\mathrm{y}$ vida litúrgica ${ }^{18}$.

Pero inseparables: Los sentidos de "civitas Dei" y " Ecclesia" son complejos, distintos e inseparables, pues se reducen a considerar una misma realidad bien en estado de perfección o bien "in fieri"; en su vida interna, o en su dimensión externa. La Iglesia en la que nosotros vivimos ahora, es la "civitas Dei", "in fieri", en proceso dinámico en "excursusprocursus" 19 , pero distinta de la "civitas Dei", "in facto esse", en estado de perfección. Dicho de otra manera la Iglesia en su sentido pleno equivaldría con propiedad a la "civitas Dei-reino de Dios o Christus totus", y la "civitas Dei in fieri" sería equivalente a la Iglesia peregrina, en afán de perfección -semper reformanda- (cuerpo de Cristo). La caridad es su rasgo definitivo aplicado tanto a la peregrina en la tierra, como a la del cielo. Como el amor terreno hace la ciudad terrena y humana, así la caridad hace a la Iglesia y a la ciudad de Dios ${ }^{20}$.

Pero de ninguna manera esto nos puede llevar a admitir la existencia de dos Iglesias, una aquí y otra la del cielo, sino una y única, pero en dos

${ }^{15}$ En. Ps. 30, s. 3, 3; Retr. 2, 6; Ciu. 10, 6; Ib. 15, 1-2; En. Ps. 149, 5.

${ }^{16}$ Ciu. 8, 24, 2; Ib.13, 16, 1; Ib., 16, 2, 3.

${ }^{17}$ Diccionario de San Agustín, 273; Ord. 2, 10, 29.

${ }^{18}$ Ciu. 20, 9, 1-2; Diccionario de San Agustín, 664-7.

${ }^{19}$ Diccionario de San Agustín, 670-71; Ciu. 10, 32, 4; Ib., 1, 35; Ib., 11,1.

${ }^{20}$ Santos Santamarta: "Introducción general a La Ciudad de Dios", 29-30*. 
situaciones distintas, "en dos tiempos de la misma Iglesia, no dos Iglesia"21, según se trate del proceso de construcción, o del de consumación; un mismo edificio en proceso de construcción (en la tierra), o ya terminado (en el cielo): La totalidad del Cuerpo místico comprende los dos momentos o partes unidas a su única Cabeza ${ }^{22}$.

Distingue tres clases de miembros pertenecientes a la Iglesia, o más bien dos clases, porque la tercera se ha excluido a sí misma de la Iglesia: "Los fieles buenos y santos siervos de Dios, que no sólo están en la Iglesia, sino son la misma Iglesia, porque su justicia es compatible con los defectos ignorancias y fragilidades; y los otros que están en la Iglesia pero no pertenecen a su misma estructura, porque están como la paja está con el trigo; son los simples pecadores que conservan la unidad de la fe, participan de los sacramentos, de la predicación de la palabra divina, de la oración dominical y del reconocimiento de la autoridad de la Iglesia; su función sirve para acrisolar a los buenos y mostrar la misericordia de Dios que los incorpore al organismo eclesial. Pero existe una tercera clase ( $i$ se pueden llamar miembros de la Iglesia?): los que han roto las redes -ruptura radical externa o no con la Iglesia-: cismáticos, herejes, han roto los vínculos de la paz y de la unidad. Estos están fuera y separados, al menos, espiritualmente, de la Iglesia" ${ }^{23}$.

\section{2.b. "Civitas terrena" y civitas política (Estado), distintas, pero in- separables en sus miembros}

En modo alguno puede hoy identificarse la "civitas política (o Estado) con la "civitas terrena" en una interpretación seria de san Agustín. En la antigüedad fue la interpretación comúnmente admitida, origen propicio para que naciera el llamado "agustinismo político", y el concepto medieval de "cristiandad".

El término "Estado", cargado en la actualidad de matizaciones, viene, en general, configurado por unos intereses comunes y fundamentales que posibilitan la libertad y realización ciudadanas en el concierto del bien

\footnotetext{
${ }^{21}$ Agostino Trapé: Patrología III, BAC, Madrid 1981, 535.

${ }^{22}$ Ench. 56, 15; Cf. Breuic. 9,16 (día tercero); Ib., 10, 20. BAC. T. XXXII).

${ }^{23}$ Bapt. 7, C. Don. 7, 51, 99.
} 
común público, al tiempo que, la vinculación entre sus miembros asegura el progreso y la paz societarios. Este libre y adecuado juego realza, en forma de trueque, la "tranquillitas temporalis ordinis".

Pero también se ha dado y particularmente en la modernidad, el Estado absolutista, represivo de los derechos fundamentales del hombre, el cual nunca podría reconocer Agustín como Estado por ser inhumano y la típica representación de la "civitas diaboli, sive terrena". Un Estado tal, al modo, por ejemplo de Maquiavelo, conformaría un anti-Estado, y por ello, una anti-Iglesia, un Estado-Dios ${ }^{24}$. Equivaldría a la "civitas terrena", porque implicaría un endiosarse de sí propio, un amar el mal, un amar desordenado, y, en fin, la disensión total, carente de toda justicia.

Un Estado de tal hechura, no podrá mantenerse, al faltar todo resquicio de justicia y de paz (concordia). Es la contestación que nos la proporciona magistralmente La Ciudad de Dios. Y en la actualidad los estudios filosófico-históricos de Fustel de Coulanges, Barker, Boissier, Ortega y Gasset, A. Toynbee, Mircea Eliade, Carlos Castro, etc., confirman, hasta la saciedad, la misma tesis ${ }^{25}$.

Pero en todo caso, tanto Estado de derecho como un Estado totalmente injusto pertenecen, aunque de muy diverso modo, a la "Civitas terrena", porque esta en su excursus no siempre excluye su participación en los valores naturales-humanos. Y aquí es precisamente, donde encontramos el punto histórico de inflexión, común a "civitas religiosa y a la civitas política" (Iglesia y Estado).

\section{2.c. “Civitates históricas Iglesia-Estado", distintas, pero interdepen- dientes y mezcladas en sus miembros:}

Infinidad de veces el término "civitas" se resuelve en otras tantas significaciones histórico-temporales, concretas, i.e., la variedad de este referente es la sociedad, la ciudad, la comunidad concreta, histórica y real.

Dentro del significado básico y común de "civitas", discurre identificado en la práctica con "sociedad-comunidad". Así, esta "civitas-commu-

${ }^{24}$ J. Pegueroles, O.c., 113. Un estado así se identifica con la "Civitas diaboli” en el De Civitate Dei.

${ }^{25}$ Ciu. 4, 4; Ib., 19,4; F. de Coulanges; C. Castro; 58 ss.; Toynbee, en particular el tomo XIII; M. Eliade, 328 ss.; Ortega y Gasset, 151-52. 
nitas", referida a sociedades concretas y establecidas, Agustín las deja muy bien identificadas, diferenciendo a cada una, dentro de su propia condición: a la "civitias christiana" con su sentido y función espiritual-integral, i.e., la Iglesia, y a la "civitas política", con su dimensión y quehacer temporal-cívico, i.e., el Estado. Se dan, a su vez, entro de la Iglesia y el Estado, sus respectivas matizaciones, según iremos viendo. Los términos de "civitas, societas, gens (natio), populus, res-publica, regnum", sin ser idénticos, corren, con frecuencia, en paralelo sobre unas mismas líneas humano-conceptuales $^{26}$.

La civitas agustiniana en su acepción de "societas", y en contra del entender de un Jacques Maritain, comporta siempre un rango de "communitas", de vínculo afectivo, de libertad societaria, de interés y amor común con sabor político-social. La "civitas agustiniana" ejerce aquí funciones no tanto de politeia griega (formas de estado), cuanto de alma de la "polis" en su dimensión comunitaria". El sentido ordinario de "civitas política (societas-communitas política) -al modo de la "polis" griega- lo expresa constantemente Agustín al centrarlo en la "concordia" (concors) ${ }^{28}$.

Siempre, y en todo caso la civitas política guarda vinculación con la "civitas religiosa (christiana-Ecclesia)", al venir constituida formalmente por una multitud racional de hombres en concorde convivencia, y realizar la función temporal que no puede ser ajena a una civitas christiana necesariamente encarnada en el mundo. Los medios y fines propuestos para el logro de esa convivencia son quienes nos permitirán catalogar a una instancia histórica (institución concreta) de religiosa, o de política.

Un supuesto Estado, que se opusiera, u obstaculizara sistemáticamente -en la práctica- la dimensión religioso-trascendental propia del hombre y de la Iglesia, dejaría "ipso facto" de considerarse Estado humano, o comunidad humana política, i.e., Estado de Derecho. Tendríamos el caso del Estado absolutista, claramente injusto, absorto de modo permanente y total por los bienes temporales, que verificaría la encarnación

${ }^{26} \mathrm{~J}$. Maritain, O.c., $15 \mathrm{ss}$.

${ }^{27}$ Ib., 16-18; Del Estal, 423; Cf. Werner Jaeger, Paideia: los ideales de la cultura griega, 367-69. FCE. México, 1962; Ib., 441; Ib., 593; León Robin, El pensamiento griego y los orígenes del espíritu científico, 254 ss. Uteha. México, 1956.

${ }^{28}$ Ciu., 1, 15, 2; Ib. 15, 8, 2; Ib., 19, 24; Ord. 2, 18, 48. 
de la "civitas terrena", sin conexidad posible con la Ecclesía. Tal Estado absolutista, no sería otra cosa que una inmensa piratería ${ }^{29}$.

En principio y partiendo de la aceptación básica que toda "civitas política" o Estado debe cumplir en tanto representante que es de velar por el bien cívico y social, las relaciones Iglesia y Estado lucen necesarias. El problema nunca debidamente resuelto, verdadero problema político, consiste en hacer viable y concordante el modo de sus mutuas relaciones.

\section{Relación de interdependencia dialéctica Iglesia-Estado:}

Constatada así, la existencia conjunta Iglesia y Estado con sus miembros mezclados (comunes) y cada una con su misión y función propia, luce elemental respetar e, incluso, favorecer cuando el principio de subsidiariedad lo pida, sin intromisión, ni subordinación de parte. Desde aquí hay que entender la tesis agustiniana de la mutua interdependencia, como relación dialéctica necesaria, san Agustín, al mismo tiempo que contrapone la patria carnal a la patria que nace por la fe, donde florecen los santos en una eternidad sin término ${ }^{30}$, mostrándose defensor del orden político ${ }^{31}$, contrapone, a su vez, la república o sociedad política con sus virtudes naturales a la ciudad (sociedad) de los impíos. Así contrapone el ejemplo de Catón y sus enseñanzas al ejemplo y enseñanzas de los impíos ${ }^{32}$. En contrapartida con la ciudad de los impíos, "cuando en la república se practican las virtudes entonces florece de veras. Todas esas virtudes-costumbres se enseñan y aprenden en nuestras iglesias (in ecclesiis) ${ }^{33}$. Aquí, en el reconocimiento de los valores naturales dentro de la ciudad o república, reside el punto de inflexión Iglesia-Estado ${ }^{34}$.

En las dos ciudades, Iglesia-Estado, domina la ley de los contrarios (complexio oppositorum), o la dialéctica de los dos amores y dialéctica

${ }^{29}$ Ib. , 4, 4; Cf. E.L. Fortin, 181 ss (177-204); L. Strauss-J. Cropsey (Compils.), Historia de la filosofía política. FCE. México, 2001.

${ }^{30}$ Ep., 91, 6.

${ }^{31}$ Ib., 91, 3; uera rel. 6, 10-11.

${ }^{32} \mathrm{Ib}$., 91, 3-4.

${ }_{33}$ Ib., 91, 3; En Ps., 136, 9.

${ }^{34}$ E.L. Fortin, O.c., 197. 
razón-fe-intelección. Esta dialéctica pertenece a lo profundo de la historia humana, "la dialettica dell'Uomo Dío" opuesta a la dialéctica del materialismo marxista en el sentido más desafiante para todo racionalismo; la inspiración cristocéntrica de La Ciudad de Dios ilumina el sentido de toda la historia ${ }^{35}$.

Esta dialéctica Iglesia-Estado queda bien establecida en los comentarios que Agustín hace a los textos evangélicos aparentemente contrarios (opuestos), "cuando no hay cuestión alguna de discordancia entre ellos". "El que no está conmigo está contra mí" y "El que no está contra mí está conmigo" "36. Como si pudiese no estar con él el que no está contra él. "En tanto no está alguien con él en cuanto está contra él, y en tanto no está contra él, en cuanto está con él". "No se le puede prohibir hacer aquello que era bueno, y en lo que está con ellos (el que hacía milagros y no estaba en el grupo de los discípulos)...". "Así actúa la Iglesia Católica al no reprobar en los herejes los sacramentos comunes; en lo que a estos respecta, ellos (los donatistas) están con nosotros y no contra nosotros. Pero desaprueba y prohíbe la división y separación, o alguna sentencia contraria a la paz y la verdad; pues en esto están contra nosotros, porque en esto no están con nosotros, ni con nosotros recogen y, en consecuencia, desparraman" ${ }^{37}$. Estas expresiones agustinianas referidas, en particular a los herejes-cismáticos (donatistas), "a fortiori", son aplicables a las distintas instancias políticas en su devenir con la Iglesia.

Dice C. Dawson que la obra de Agustín produjo efectos profundos y revolucionarios en el mundo occidental: "Descubrió a los historiadores cristianos el proceso dinámico en que se realiza el propósito divino; explicó a los hombres las razones de que la personalidad individual sea la fuente y el eje del proceso dinámico; y finalmente, logró que la Iglesia occidental tuviera plena conciencia de su misión histórica y llegara a constituirse en el principio activo de la cultura europea" 38 .

${ }^{35}$ Higinio Giordani, Le due Cittá, 17-23; Cit. en 98*.

${ }^{36}$ Mt. 12, 30; Mc. 9, 38-39; Lc. 9, 50 y 11, 23; Cf. S. 260 A, 3; Ib., 283, 4; Ib., 71, 4; Io. Eu. tr. 111, 2; Cath. fr. 16, 40; Ep. 208, 6; Ib., 155, 4, 15.

${ }^{37}$ Cons. Eu. 4, 5, 6.

${ }^{38}$ C. Dawson, O.c.,183-8. 


\subsection{Existencia de un "quid medium naturale-humanum":}

En este contexto y atendiendo al fin específico de cada una de estas dos civitates históricas, descubrimos en Agustín, una realidad humana de bienes-valores naturales, que las fundamentan y que nosotros convenimos en llamar un "quid medium naturale humanum", o realidad común a compartir tanto por la Iglesia como por el Estado. Pocos autores han fundamentado y defendido los valores de la cultura griega y latina como lo hiciera Agustín, para quien esta cultura "legó al mundo cristiano sus ornamentos y joyas para enriquecerse y realzar su propia hermosura" 39 .

A esta realidad conformada por miembros de una y otra ciudad histórica, Ch. Journet la llama "civitas hominis", y H.-I. Marrou "tertium quid" -saeculum-; y nosotros, creemos que adecuándonos mejor al pensamiento agustiniano, la podemos llamar "quid medium humanum naturale", porque sin oponerse a la Iglesia como "communitas fidei", ni al Estado como estructura política, conforma una realidad filantrópica de bienes-valores naturales humanos, a tenor de la ley natural (razón natural). No es propiamente "una tercera civitas" (Journet), al no estar en el mismo orden de las "dos civitates metahistóricas", en el cual solo se admiten dos "civitates" con sentido propio, y esta sería una "tercera civitas", cosa inaceptable en Agustín. Y tampoco es adecuado reconocer un "tertium quid" -saeculum- (Marrou), que al ser interpuesto como realidad histórica entre dos realidades metahistóricas, deja desdibujadas las realidades "Iglesia y Estado" así como su funcionalidad histórica. En ese "tertium quid" real, al no hacerse distinción alguna entre lo bueno (natural) y lo malo (anti-natural) existentes en el mundo del hombre), resulta una inutilidad para nuestro propósito de establecer cómo y cuáles han de ser las vinculaciones Iglesia y Estado.

Por eso, esta tercera realidad histórica (saeculum) en la cual están inmersas por igual la Iglesia y el Estado, induce varios interrogantes: ¿la Iglesia y el Estado quedan como realidades diferenciadas y separadas? Y si quedan, ¿qué y cómo ejerce cada uno su papel? Y si no quedan, ¿cuál es su razón de ser? Sin poner claridad en este punto, en absoluto se resuelve, ni aclara nada. Porque de lo que aquí se trata es de diferenciar en

${ }^{39}$ Santos Santamarta, O.c., nota 55, pp. 994 s.; cf. Eugenio d'Ors, La Ciencia de la cultura. Madrid, 1964. 
el "saeculum" las realidades de valores, de aquellas de los disvalores. Las realidades de valores han de ser compartidos por la Iglesia y por el Estado, mientras las realidades de disvalores han de ser contrapuestos (tolerandos, soportandos,... necesarios, por otra parte, para la purificación de lo auténtico).

Parece lógico, por tanto, que llamemos, más bien, "quid medium humanum naturale" $"$, a la existencia de esa realidad histórica variable y perfectible, que sería el factor común o ámbito compartido por la Iglesia y el Estado de derecho; medio humano, o conjunto de bienes-valores humanos, como fundamento ideal para las relaciones Iglesia y Estado. Con lo cual no caeríamos, por una parte, en ninguna teocracia eclesiástica, ni en concepción alguna de "cristiandad", una y otra tan alejadas del pensamiento agustiniano; y por otra, evitaríamos todo absolutismo de Estado, lo mismo que todo relativismo absoluto, ambos tan en contradicción con la mente de Agustín ${ }^{41}$.

\subsection{Confirmemos la razón de ser de este "quid medium naturale-hu- manum":}

Agustín, al tener siempre como centro prioritario de preocupación la obra de la encarnación-redención salvífica en y de la historia, se le ha denostado, en el punto que nos ocupa, de las relaciones Iglesia y poder político, cuando en realidad él acepta y defiende, sin ambages, el "medium naturale humanum" como base común a ambas instituciones. Por eso, es muy importante, para nuestra reflexión, hacer expreso su pensamiento. Veamos, si no en cuatro considerandos, que son constituyentes básicos mutuamente implicantes en la composición de las civitates (sociedades) históricas: Iglesia-Estado y en sus mutuas relaciones, como:

\section{a. La concordia social humana}

El concepto de ciudad-sociedad supone una pluralidad cuantitativa y una unidad cualitativa (reunión de seres humanos que comparten un

${ }^{40}$ Autores como Juan Pegueroles, Lourdes Bassols, etc. dan por buena la tesis del "tertium quid" sin especificación alguna. J. Pegueroles, O.c., 122; L. Bassols, San Agustín, 170s. Barcelona, 2007.

${ }^{41}$ José Morán, "Introducción general”, en: La Ciudad de Dios, BAC XVI. 
factor común). Sin pluralismo no hay ciudad; sin alguna forma de unidad tampoco: "Es una multitud de hombres unidos entre sí por algún vínculo de sociedad" ${ }^{42}$,-“civitas, hoc est societas"-43. Pero este vínculo, en Agustín, se especifica por la concordia, base común de toda convivencia humana: "concors hominum multitudo".La concordia (concors) base de toda sociedad estable cuyo enemigo la "discordia" (discors), la disensión: "El pueblo es un conjunto de ciudadanos para los cuales es peligrosa la disensión (dissentire: non unum sentire). "No es posible que subsista, por falta de concordia, la sociedad, cuando rehusamos creer" $"$.

"Se trata de aquellas ciudades..., lo que podría llamarse el pueblo bajo de esta ciudad (del mal)... Luego donde hay un rey, un senado, ministros y pueblo, existe la ciudad; pero no se darían tales cosas, los vicios en las malas ciudades, si primero no se hallasen en cada uno de los hombres, que son como los elementos y gérmenes de las ciudades. Amortiguados, pues, los vicios se pacifica el alma, se asigna el debido empleo de la justicia y de la buenas obras, y se dispone el hombre a la conquista de la paz y de la bienaventuranza" ${ }^{45}$.

\section{b. El amor humano}

El amor que es social por naturaleza, por creación, forma a un triple nivel la "concors hominum multitudo": domus, urbs, orbis terrae ${ }^{46}$. Las sociedades (civitates: Dei et sui) se definen por su amor, porque el amor es la definición del hombre completo. Pero, si su condición de "civitas" identifica a las dos, cada una de ellas se diferencia especificativamente de la otra por la clase de su amor (amor Dei et sui), siendo el amor su elemento discriminante y singular. Porque, así como el amor diferencia a los hombres en dos clases, así también, por el amor se diferencian las dos ciudades.

${ }^{42}$ Ciu. 15, 8, 2; Ib., 1, 15, 2; Ib., 19, 24.

${ }^{43} \mathrm{Qu}$. Eu. 2, 46 .

${ }^{44}$ Ord., 2, 18, 48: "Populus una civitas est, cui est periculosa dissensio: quid est autem dissentire, nisi non unum sentiré?". Pueblo hombres asociados por la concorde comunidad de bienes (objetos) amados" (Ciu. 2, 15,2; Ib. 19,24). Aquí reside la distinción entre pueblo y masa, quida la concorde unidad y tenemos la turba (Ciu. 19, 21; S., 103, 4; F. inuis., 3, 4.

${ }^{45}$ En. Ps. 9, 1,8.

${ }^{46}$ Ep. 151, 9. 
Pero el "amor Dei", a nivel histórico-temporal, hay que desdoblarlo en dos: un amor, que es propio de Dios y que actúa en la creación (constitución) de la ciudad, y un amor humano, expresión de aquél, puesto en la entraña de la criatura racional, y con el cual responde el hombre para cooperar en la edificación del reino de $\operatorname{Dios}^{47}$. Ciertas formas de amor: el de la gloria, el honor, la alabanza, la lucha por la independencia de la patria, por la libertad.., que son formas naturales de amor que mantenían a raya otras pasiones que envilecen a los hombres, estimularon a los romanos a emprender grandes y maravillosas obras ${ }^{48}$.

Por eso ahí tenemos la mejor definición que Agustín nos da de "ciudad-sociedad humana": "Populus est coetus multitudinis rationalis, rerum quas diligit concordi communione sociatus. Y para saber qué es cada pueblo, es preciso examinar los objetos de su amor" ${ }^{\prime 4}$.

\section{c. La esperanza-confianza humana}

Hay una esperanza vulgar y reprensible, que estimula a la maldad, y otra llamada natural y civil, a esta pertenecen tantas esperanzas humanas y honestas, como la de los novios que esperan casarse y fundar una familia. Esta esperanza se relaciona con la posesión y goces de los bienes temporales. Y existe una tercera esperanza, la esperanza cristiana, cuyo objeto es Dios, como Bien supremo.

"Vemos, en efecto, a los hombres esperar ahora muchas cosas terrenas. Limitándonos a los aspectos mundanos, ningún hombre vive sin esperanza, y hasta el momento de la muerte no hay nadie que no la tenga. Los niños tienen esperanza de crecer, de instruirse, de saber; los jóvenes, de casarse y tener hijos; los padres, de alimentar a los hijos, de instruirlos, de ver crecidos a quienes acariciaban de niños, por referirme de manera particular al núcleo de la esperanza humana, que es como lo más natural, lo más excusable y lo más frecuente. Todas estas cosas causan deleite, son hermosas, son buenas. Busca quién las hizo: él es tu esperanza y él será luego tu posesión" ${ }^{50}$. Y esta tercera, es "la esperanza cristiana, donde Cristo

\footnotetext{
${ }^{47}$ Santos Santamarta, O.c., 26*

${ }^{48}$ Сiu. 5, 12, 1-6; Ib. 5, 18, 1 .

${ }^{49} I b ., 19,24 ; I b ., 1,15,2 ; I b ., 15,8,2$.

${ }^{50} S .313$ F 2-3 )Denis 22).
} 
es la esperanza universal y verdadera" para todos los pueblos, "porque la vida de la vida mortal, para el cristiano, es la esperanza de la vida inmortal" 51 .

Pero la esperanza no se mantiene sin la base de la fe-confianza (confidere) humana. "Si no admites la buena voluntad de los otros, de tal manera se perturban las relaciones entre los hombres que es imposible la vida social... Vendría una confusión espantosa si desapareciera de la sociedad humana la fe, porque desaparecería la amistad, porque es necesario creer en el afecto de los amigos, en nuestros padres..."52.

La Iglesia es la esperanza de todos los continentes... Muchos rompieron las redes de la Iglesia y salieron fuera, porque dijeron que no podían tolerar dentro de la red a los malos peces capturados, y por esto, más bien, se hicieron ellos peores peces que aquellos a quienes ellos dijeron que no podían tolerar. Aquella red (la Iglesia) capturó peces buenos y malos... “¿Ea!, ciudadanos de Jerusalén, que estáis dentro de la red y sois peces buenos, tolerad a los malos, no rompáis la red. Con ellos estáis en el mar, mas no estaréis con ellos en las canastas" ${ }^{\prime 53}$.

\section{d. La ley natural de contenido variable-perfectible, discriminante para el cumplimiento atemperado de las leyes civiles}

"No he venido a abolir la ley, sino a darle cumplimiento". Cumplir con el deber ciudadano, y con el pago de impuestos. La ciudad (urbs-civitas) constituida desde la familia (domus), ha de obedecer a la ley natural y civil, lo que implica en Agustín aceptar el orden social siempre que no vaya contra la ley divina ${ }^{54}$.

${ }^{51}$ En Ps. 103, 17

${ }_{52}$ F. inuis., 2, 4; Ib., 1, 1-2; Cf. Util. cred., 12, 26; Nat. et gr., 2, 2; Trin., 13, 1, 2-4.

${ }^{53}$ En. Ps. $64,9$.

${ }^{54} \mathrm{Ciu} .19,16-17$. "La casa debe ser el principio y el fundamento de la ciudad. Todo principio dice relación a su fin, y toda parte a su todo. Por eso es claro y lógico que la paz doméstica debe redundar en provecho de la paz cívica... De donde se sigue que el padre de familia debe guiar su casa por las leyes de la ciudad, de tal forma que se acomode a la paz de la misma"... "La familia humana que no vive de la fe busca la paz terrena en los bienes y comodidades de esta vida temporal... En cambio, aquella cuya vida está regulada por la fe está a la espera de los bienes eternos... He aquí que el uso de los bienes necesarios para esta vida mortal es común a las dos clases de hombres y a las dos familias (casas; pero cada uno tiene un fin propio y un pensar muy diverso el uno del otro". 
La ley temporal siendo justa puede modificarse justamente según lo exijan las circunstancias de los tiempos es útil para todos ${ }^{55}$; ella regula la posesión personal de los bienes dentro de la convivencia social, las artes liberales, la libertad por la que se creen libres los que sirven a otros señores, las libertades familiares, las libertades del Estado ${ }^{56}$. La ley dada para la defensa justa del pueblo no es apasionada ${ }^{57}$. El concierto mutuo entre pueblos o naciones, firmado por la costumbre o la ley, no se quebrante por ningún capricho de ciudadano o forastero, porque es indecorosa la parte que no se acomoda al todo, porque es ley primordial de toda sociedad humana obedecer a sus reyes, siempre que no vaya contra el bien de la propia sociedad, de la ley suprema" ${ }^{58}$.

"Dad al César lo que es del César y a Dios lo que es de Dios" (Mt. 22, 21). "Al César los dineros, a Dios, vosotros mismos"59. "El dinero te será bagaje para el exilio, no incentivo de la codicia; has de usarlo según la necesidad, no disfrutarlo para deleite"60. "Así como el César busca en el dinero su imagen, así Dios, en el hombre busca la suya"61.

Los impuestos los pagan los extraños, no los hijos, "sin embargo, para no darles mal ejemplo, ve al mar, echa el anzuelo, coge el primer pez que pique, ábrele la boca y encontrarás una moneda de plata. Cógela y págales por mí y por ti" (Mt.17,26-27). Conocía otro derecho por el cual no debía pagar, pero pagaba en razón a los débiles, para que no se escandalizaran ${ }^{62}$.

${ }^{55}$ Ciu. $1,6,14$.

${ }^{56} \mathrm{Ib} ., 1,15,32$.

${ }^{57} \mathrm{Ib} ., 1,5,12$.

${ }^{58}$ Conf. 3, 8, 15. Ciu. 19, 15: "A pesar de todo, esta misma esclavitud, fruto del pecado, está regulada por una ley que le hace conservar el orden natural y le prohíbe perturbarlo. Porque si no se hubiera quebrantado esta ley, no habría lugar a castigo alguno de esclavitud. Por esta razón el Apóstol recomienda incluso a los esclavos (servi, de servare, conservar la vida a los esclavos de guerra) que se sometan de corazón a sus amos, y les sirvan de buena gana... hasta que pase la injusticia"; $I b ., 4,15 . Q u$. 6,10.

${ }^{59}$ Io. eu. tr. 40, 9.

${ }^{60} \mathrm{Ib}, 40,10$.

${ }^{61} \mathrm{Ib} ., 41,2 ;$ S. dom. m., 2, 20, 70.

${ }^{62}$ Ep. 83,5. 


\section{Conclusión: Propuesta marco de filosofía política}

Esta estructura común nos da luz para unir y discernir personas y grupos sociales antagónico. La antropología nos introduce en la sociología de los dos reinos... Por eso las Confesiones se han considerado como una introducción a la Ciudad de Dios. El drama de la vida individual, se parece al drama del género humano en el curso de los siglos ${ }^{63}$.

El dinamismo inmanente de la historia gira en la rueda de estas fuerzas que resumen los ideales humanos: amor, libertas, beatitudo, pax, asiento para que actúe la iluminación de la ciudad de Dios. Junto a la dialéctica intelectual está la tarea moral, que también exige la condición terrena de los miembros de la ciudad de Dios. La cultura misma y la sabiduría cristiana tienen su corona en la perfección moral de los cristianos. La tarea cristina consiste en elevar todo el orden temporal, o de las realidades terrestres, políticas y sociales, partiendo del "quid medium naturale humanum" de bienes y valores (virtudes cívicas). Es lo que hacía el Santo contra los que tenían como incompatibles las virtudes evangélicas con la grandeza de la ciudad terrena o del imperio. "Comprendamos las enseñanzas del Evangelio... como la mejor garantía para el bienestar y progreso del imperio" ${ }^{64}$.

"El honor temporal y el poder mandar y dominar tiene su atractivo, de donde nace la avidez de venganza. Sin embargo, para conseguir todas estas cosas no es necesario abandonarte a Ti, ni desviarse un ápice de tu ley. También la vida que aquí vivimos tiene sus encantos, por cierta manera suya de belleza y por la correspondencia que tiene con las bellezas inferiores. Cara es, finalmente, la amistad de los hombres por la unión que hace de muchas almas con el dulce nudo del amor. Por todas estas cosas y otras semejantes se peca cuando por una inclinación inmoderada preferimos estos bienes inferiores abandonando, los mejores y sumos. Estos bienes temporales, sin duda son apetecibles, aunque comparados con los superiores y beatíficos son viles" 65 .

De donde tenemos que el "amor Dei" desdoblado en dos, junto al "amor sui", generan tres clases de hombres, o de realidades históricas: la

${ }^{63}$ Cf. uera rel. 27, 50. José Morán, O.c., LIV ss; Santos Santamarta, O.c., 23*.

${ }^{64}$ Ep., 138, 2, 15.

${ }^{65}$ Conf. 2,5,10-11. 
de los impíos "de facto" (los anti-sistema radicales), la de los fieles a la Ecclesía, y la de los del Estado de derecho, siendo el "Christus ut Homo" el mediador universal y centro-eje de toda la dinámica de la historia. Por Él han de reinar los reyes y los jueces impartir justicia. "Esta senda no es de una nación, sino de todas las naciones" $"$.

"San Agustín, dice Umberto Pucci, ha llegado a ser uno de los mejores y más eficaces cooperadores para que se perpetuase la civilización romana en el mundo cristiano y se conservase el patrimonio intelectual del clasicismo. Él representa la nueva orientación de los espíritus"6? 